\title{
Energy-efficiency approach for long range wireless communication
}

\author{
Le Cong Nga, Cuong Pham-Quoc ${ }^{*}$, Tran Ngoc Thinh
}

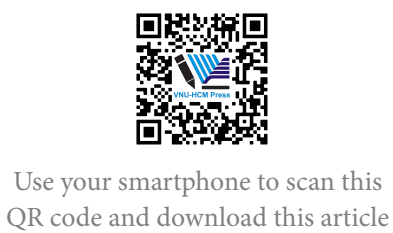

Ho Chi Minh City University of Technology, Vietnam National University Ho Chi Minh City, Vietnam

Correspondence

Cuong Pham-Quoc, Ho Chi Minh City University of Technology, Vietnam National University Ho Chi Minh City, Vietnam

Email: cuongpham@hcmut.edu.vn

History

- Received: 05-8-2019

- Accepted: 03-9-2019

- Published: 13-11-2020

DOI : 10.32508/stdjet.v3i3.532

\section{Check for updates}

Copyright

(c) VNU-HCM Press. This is an openaccess article distributed under the terms of the Creative Commons Attribution 4.0 International license.

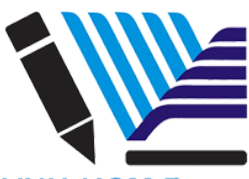

VNU-HCM Press

\begin{abstract}
According to recent research, the wireless sensor networks which consume low levels of energy become more and more popular nowadays, so the research trend of optimizing energy for wireless sensor networks is rapidly increasing. LoRa ${ }^{T M}$ technology is a modulation technique that provides long-range transfer of information and low power consumes. Besides, LoRaWAN ${ }^{T M}$ is a network protocol that is optimized for battery-powered end devices. The LoRaTM and LoRaWAN ${ }^{T M}$ can be considered a suitable candidate for wireless sensor networks, which can reduce power consumption and extend the communication range. In the post personal computer era, when most devices are battery-based, the more energy consumption saved the better and more attractive users. In this paper, we study adaptive mechanisms in the transmission parameters of the LoRaTM network and proposed an energy-efficiency solution for the adaptive algorithm. The proposed algorithm helps reduce the energy consumption of LoRA-based internet of thing system while keeping all quality parameters unchanged. This research not only introduced the reference hardware of a sensor node in wireless sensor networks but also conducted experiments on typical LoRaTM network infrastructure. We conduct three different experiments to validate our proposed algorithm with real systems which use air quality sensors and an ultra-low-power micro-controller unit board from Texas instruments. Our experimental results with both real systems and simulations show that we achieve at least $4 \%$ energy consumption when the proposed algorithm used. Although energy consumption is saved, the quality of services including communication range and packet arrival rate are kept unchanged. The proposed algorithm as well as the testing systems can be used for further research topics to help saving energy consumption. More energy saved can make the world greener.
\end{abstract}

Key words: LoRaTM, LoRaWANTM, Wireless Sensor Networks, Adaptive Data Rate, Energy Efficient

\section{INTRODUCTION}

Extended operation time is one of the crucial characteristics of the Internet of Things (IoT), which transmit information over wireless communication. Wireless sensor network (WSN) is a typical system of IoT, which requires data exchange and long battery life highly. There has been a noticeable increase interest in studying about optimizing energy consumption for WSN; the limited and resources constrained have motivated the research towards reducing the energy consumption of MAC protocols.

The LoRa ${ }^{T M}$ is a modulation technique owned and licensed by Semtech Corporation, which describes only the physical layer. On another hand, LoRa ${ }^{T M}$ MAC protocol is controlled by the LoRaWAN ${ }^{T M}$, which is an open standard maintained and certified by the LoRa Alliance ${ }^{T M}$.

The LoRa ${ }^{T M}$ technology enables long-distance, lowpower communication and operates in the unlicensed sub-GHz ISM band. The modulation technique of LoRa ${ }^{T M}$ based on chirp spread spectrum to achieve long-range communication with the low data rate. The transmission of LoRa ${ }^{T M}$ characterized by five parameters: spreading factor, transmission power, code rate, frequency, and bandwidth. These parameters jointly affect the communication range, data rate, and reliability of data exchange between end nodes and gateway.

The LoRaWAN ${ }^{T M}$ defines the MAC protocol and the system architecture of $\mathrm{LoRa}^{T M}$ networks. LoRaWAN $^{T M}$ is an ALOHA-based MAC protocol, which simplifies the network into a star topology to reduce the complexity of end devices. In the network architecture of LoRaWAN ${ }^{T M}$, the end devices communicate with gateways over the $\mathrm{LoRa}^{T M}$ physical layer. An end device is not associated with a specific gateway; all the gateways in the network listen and receive messages from end devices within the transmission range. The gateways simply forward received messages to a network server, and this communication takes place by using the standard Internet Protocol (IP). 
Adaptive Data Rate (ADR) is a mechanism designed to efficiently change the data rate and the transmission power of static end devices. The main goals of $\mathrm{ADR}$ are increasing the capacity of $\mathrm{LoRa}^{T M}$ network and battery life of end devices. The ADR feature is implemented on network servers and also end devices, but the end device decides on using ADR or not. The $\mathrm{ADR}$ on the network server adapts two parameters are spreading factor, and transmission power to reduce energy consumes for end devices. While the end device only changes the spreading factor to extend the transmission range when data cannot reach gateways. In this research, we introduced a solution to improve ADR algorithm, which helps to extend the battery life of end devices by adjusting parameters with lower levels of transmission power. We found out that the signal quality of LoRa ${ }^{T M}$ network is not efficiently used to optimize the transmission power in the ADR mechanism. So we conducted the research and presented an improvement for the ADR algorithm to minimize transmission power without affecting communication quality. The ADR implementation used to study and evaluate the performance of the proposed solution from an open-source software named The Things Network (TNN).

A LoRa ${ }^{T M}$ infrastructure consists of a sensor node, a gateway, a network server, and an application server. The sensor node obtains functionalities as an air quality sensor, which collected air data and sent to the gateway. After that, the gateway forwarded the data to the network server and the application server. The experimental results on this LoRa ${ }^{T M}$ network infrastructure have shown that the proposed solution can help to decrease the level of power consumption and extend the battery life of the sensor node up to four percent.

The paper organized as follows. Section II reviews recent energy efficiency researches for LoRaWAN ${ }^{T M}$, section III describes in detail about the energyoptimized solution for ADR mechanism in LoRa ${ }^{T M}$ networks. Section IV presents the system used to evaluate the proposed solution with experimental results, and the research concluded with a summary and future works in section $\mathrm{V}$.

\section{RELATED WORKS}

The study ${ }^{1}$ evaluated the selection using LoRa ${ }^{T M}$ technology for wireless sensor networks. In this study, a wire- less sensor network using the LoRa ${ }^{T M}$ technology and the LoRaWAN ${ }^{T M}$ network protocol was developed and evaluated, outlining limitations, and solutions for using multiple gateways to achieve optimal coverage. However, the research only recommended the solution but did not apply to any specific problem.

The employment of $\mathrm{LoRa}^{T M}$ long-range wireless communication technology in the industrial wireless sensor network has considered and implemented in research ${ }^{2}$. The study has shown the difference in an industrial wireless sensor network compared to traditional wireless sensor networks, thereby offering a feasible solution for the application of $\mathrm{LoRa}^{T M}$ technology to the industrial wireless sensor network. This study analyzed the essentials for implementation but has not studied the aspect of energy consumption optimization.

In the study ${ }^{3}$, the energy optimization solution was introduced to combine the LoRa ${ }^{T M}$ long-range communication technology and the Wake-up Radio (WuR) short-range communication technology to optimize power consumption. This solution provides high energy efficiency but only operates in a narrow range that does not promote the power of $\mathrm{LoRa}^{T M}$ technology.

In LoRa ${ }^{T M}$ technology, many factors affect energy consumption, and in which data transmission parameters are one of the most critical factors. These parameters can be set up initially or use the ADR feature of the LoRaWAN ${ }^{T M}$ protocol. The research trend on optimal transmission parameters in LoRa ${ }^{T M}$ technology has increasingly promoted. In particular, research ${ }^{4}$ focused on LoRaWAN ${ }^{T M}$ 's adaptive data rate (ADR) feature implemented in two opensource projects, LoRa Server and The Things Network (TTN), as well as offering a solution to increase the robustness and expand the communication range in the LoRa ${ }^{T M}$ network. However, the energy-saving factor has not been reviewed and optimized by this research. In study ${ }^{5}$, the author further analyzed ADR features, which includes two components: ADR-NODE (end device) and ADR-NET (LoRaWAN ${ }^{T M}$ network server). In this study, the open-source project The Things Network (TTN) continues to be used to evaluate ADR features. The author also introduced an optimization solution for ADR-NET, but the results of the research based on the simulated model have not been tested directly on hardware devices.

The data transmission parameters in LoRa technology deeply analyzed in the research ${ }^{6}$. The author examined these parameters and pointed out the limitations of the ADR feature in LoRaWAN ${ }^{T M}$, which could not change all the parameters but only capable of adapting the spreading factor and the transmission power. The study also provided solutions to assist in selecting the proper parameters for each problem, but 
the proposed solution requires testing on the end device to find suitable parameters, which were not efficient. The solution was given only at the model level and evaluated based on the author's calculations but has not been implemented and tested on any specific hardware.

\section{PROPOSED APPROACH}

The goal of studying in this paper was seeking a power- optimized solution for $\mathrm{LoRa}^{T M}$ network with requirements:

- Can be quickly adopted in current LoRa ${ }^{T M}$ infrastructures.

- Can be combined with other optimal solutions without any conflict.

- No change of structure of LoRa ${ }^{T M}$ end devices is needed.

These constraints have driven the study into understanding and optimizing the adaptive data rate (ADR) feature in LoRaWAN ${ }^{T M}$. This feature implemented on LoRa ${ }^{T M}$ network server, so it does not affect other components in the network. The crucial part of the ADR feature was the ADR algorithm, which calculated and determined the optimal level of power consumption in the end devices.

Analyze the adaptive data rate (ADR) algorithm.

The adaptive data rate did not clearly define in LoRaWAN $^{T M}$ specification, but this mechanism contains several operations:

- Check ADR enable.

- Calculate the uplink history.

- Get demodulation floor.

- Schedule downlink.

- Implement ADR algorithm.

The adaptive data rate (ADR) feature Figure 1, which used in this research was an implementation of The Things Net- work (TTN) framework. This implementation complied with LoRaWAN ${ }^{T M}$ specification version 1.1

In this study, the focus was on the core part of the ADR feature, the ADR algorithm, which took the role of calculating and finding the spreading factor and the optimal energy transmission for each $\operatorname{LoRa}^{T M}$ end devices in the network. The original algorithm implemented by The Things Network described as Figure 2. The ADR algorithm only focused on parameters such as signal-to-noise (SNR), demodulation floor, and the number of received uplink packages to calculate a marginal value. The marginal output value reflected the transmission quality in the LoRa ${ }^{T M}$ network, which the higher the marginal value mean the better communication quality. This value then used to increase the data rate and reduce transmission energy; this changing helped to lower power consumption on end devices.

\section{Energy efficiency solution}

In the ADR algorithm, there was another essential parameter attached to the uplink package by the gateway, radio signal strength indication (RSSI). This information represented the signal quality, as well as the ability to transmit data in the LoRa ${ }^{T M}$ network. In this paper, an energy optimization solution introduced by using the RSSI value to lower the transmission power level.

In the document ${ }^{8}$, the RSSI information indicated the quality of data transmission in a wireless network as Table 1.

Table 1: The transmission quality indicated by RSSI

\begin{tabular}{|c|c|c|c|}
\hline $\begin{array}{l}\text { Transmission } \\
\text { Quality }\end{array}$ & $\begin{array}{l}\text { Quality } \\
\text { centage }\end{array}$ & Per- & RSSI Value \\
\hline Good & $90 \%$ & & $\approx-45 \mathrm{dBm}$ \\
\hline Medium & $50 \%$ & & $\approx-75 \mathrm{dBm}$ \\
\hline Low & $30 \%$ & & $\approx-85 \mathrm{dBm}$ \\
\hline No Signal & $0 \%$ & & $\approx-96 \mathrm{dBm}$ \\
\hline
\end{tabular}

From the link between RSSI and the quality of data transmission in the $\mathrm{LoRa}^{T M}$ network, the study has proposed the optimal solution of energy consumption by reducing the transmission energy on the end devices based on the transmission quality.

The correlation between RSSI and power transmission was measurable, the higher the power transmission, the stronger the value of RSSI.

This paper has studied and implemented a function which used the knowledge in the signal quality to increase the marginal value in the ADR algorithm. This function only considered two critical thresholds were good quality when the RSSI value was equal or greater than $-45 \mathrm{dBm}$, and the medium quality is when the RSSI value is equal or greater than $-85 \mathrm{dBm}$. The transition to calculate the marginal value based on the correspondence between the transmission power and the RSSI value.This optimal function described in detail as Figure 3.

The function added to the ADR algorithm right after increasing the data rate step to make sure the output 


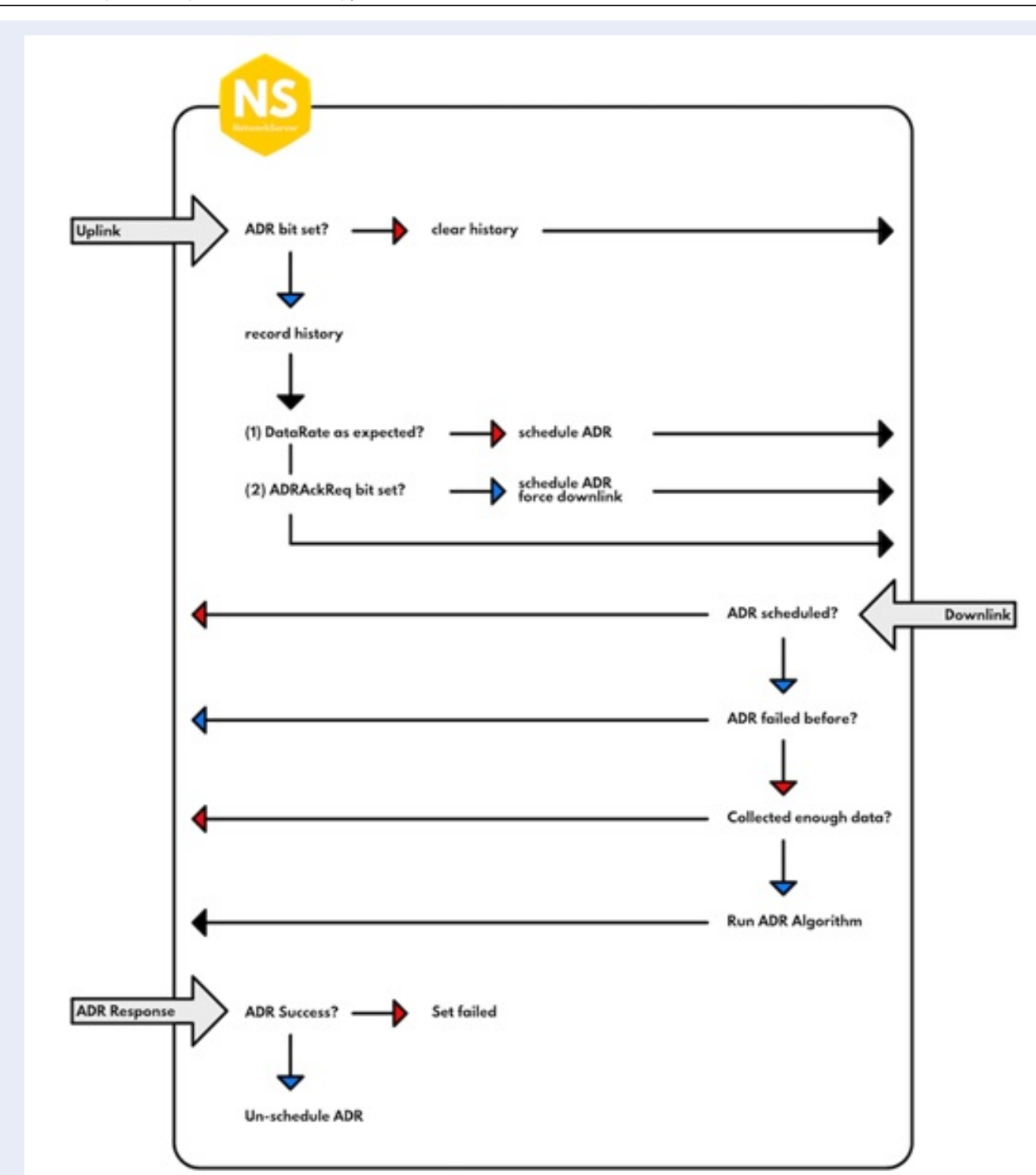

Figure 1: ADR implementation of The Things Network ${ }^{7}$.

only affected to the transmission power. The ADR algorithm operational diagram was updated as Figure 4.

\section{Evaluation of the proposed solution.}

In the LoRaWAN ${ }^{T M}$ specification for different frequency bands, there was a separate transmission power range. In this research, we used the Europe frequency band, which included eight levels of transmission power. The specification ${ }^{9}$ defined the transmission power as below:

$$
[0,2,4,6,8,10,12,14,16](d B m)
$$

Formulas (2) and (3) were used to calculate the strength of an electric current in amperes; these val- ues reflect the level of energy consumption of the end devices.

- The formula to convert energy from $(\mathrm{dBm})$ to (W):

$P_{(w)}=1 W \times \frac{10^{\left({ }^{P} \frac{d B m}{10}\right)}}{1000}=10\left(\frac{P_{(d B m)}-30}{10}\right)$

- The formula to convert from energy (W) to current intensity (A): 


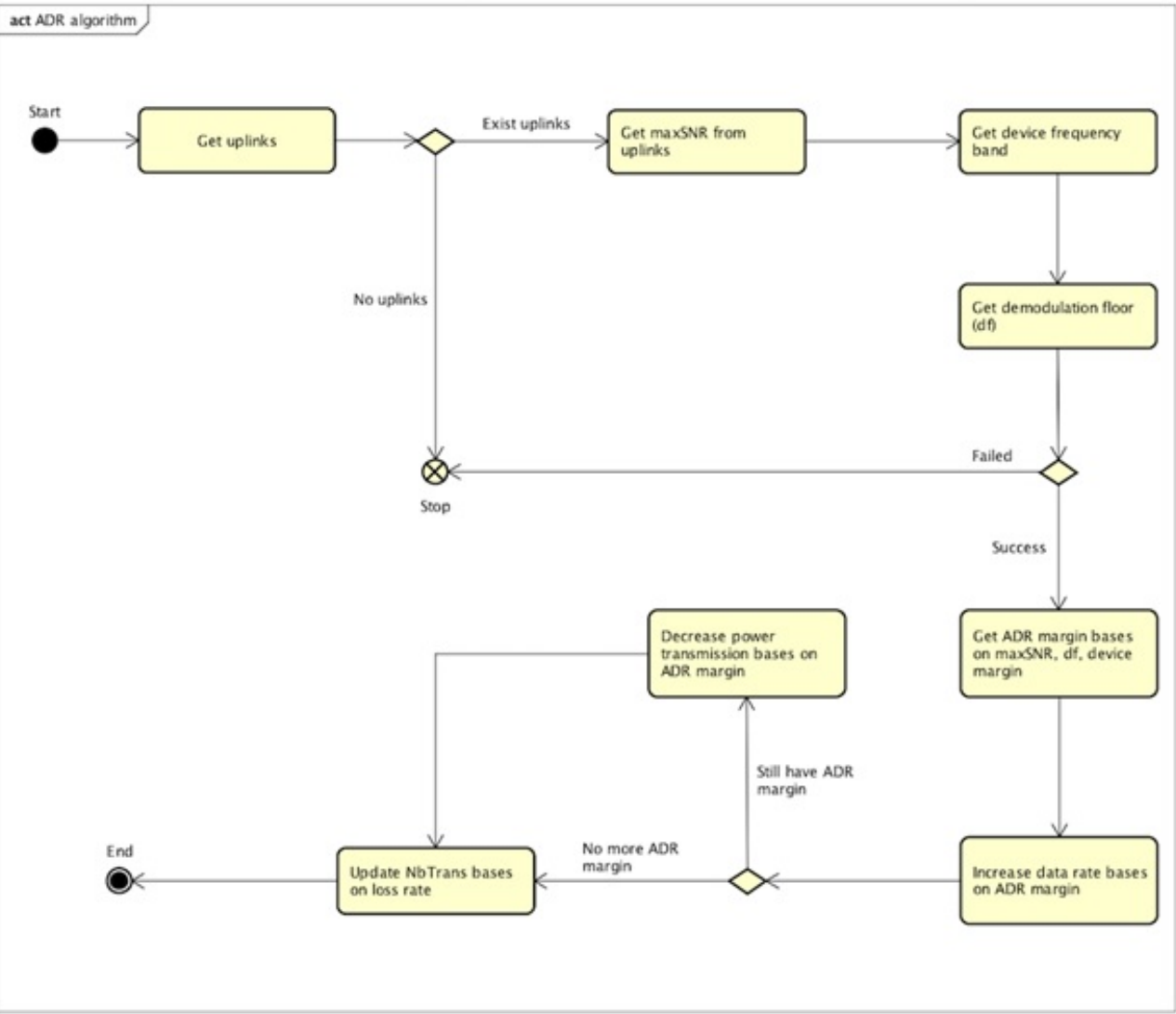

Figure 2: ADR algorithm of The Things Network ${ }^{7}$.

$$
I_{A}=\frac{P_{(W)}}{V_{(V)}}
$$

Based on two conversion formulas, together with eight transmission power levels of the ADR feature, the energy-saving levels of the optimal function described in Table 2.

The energy-saving levels calculated in Table 2 showed that the energy consumption determined by the transmission power parameter of the LoRaWAN ${ }^{T M}$ was relatively high. The energy could save up to $7.6 \mathrm{~mA}$ at 3.3 voltage, which could extend a significant amount of battery life for the end devices.

\section{EXPERIMENTAL RESULTS}

In this section, We introduced a LoRa ${ }^{T M}$ infrastructure used for conducting experiments. These experiments helped to evaluate the efficiency of the proposed solution.
Table 2: Energy Saving Levels

\begin{tabular}{llll}
\hline $\begin{array}{l}\text { Energy Saving } \\
\text { Level }\end{array}$ & \multicolumn{3}{l}{ Energy Saving } \\
& $\mathrm{dBm}$ & Watt & $\mathrm{mA}(3.3 \mathrm{~V})$ \\
1 & 2 & $\approx 0.00158$ & $\approx 0.48$ \\
2 & 4 & $\approx 0.00251$ & $\approx 0.76$ \\
3 & 6 & $\approx 0.00398$ & $\approx 1.20$ \\
4 & 8 & $\approx 0.00631$ & $\approx 1.90$ \\
5 & 10 & $\approx 0.01000$ & $\approx 3.00$ \\
6 & 12 & $\approx 0.01585$ & $\approx 4.80$ \\
7 & 14 & $\approx 0.02512$ & $\approx 7.60$ \\
\hline
\end{tabular}

\section{LoRa ${ }^{T M}$ infrastructure.}

In this paper, we constructed a simple wireless sensor network, which used LoRa ${ }^{T M}$ to transmit data. The system infrastructure in Figure 5 included four components:

- An air quality sensor. 


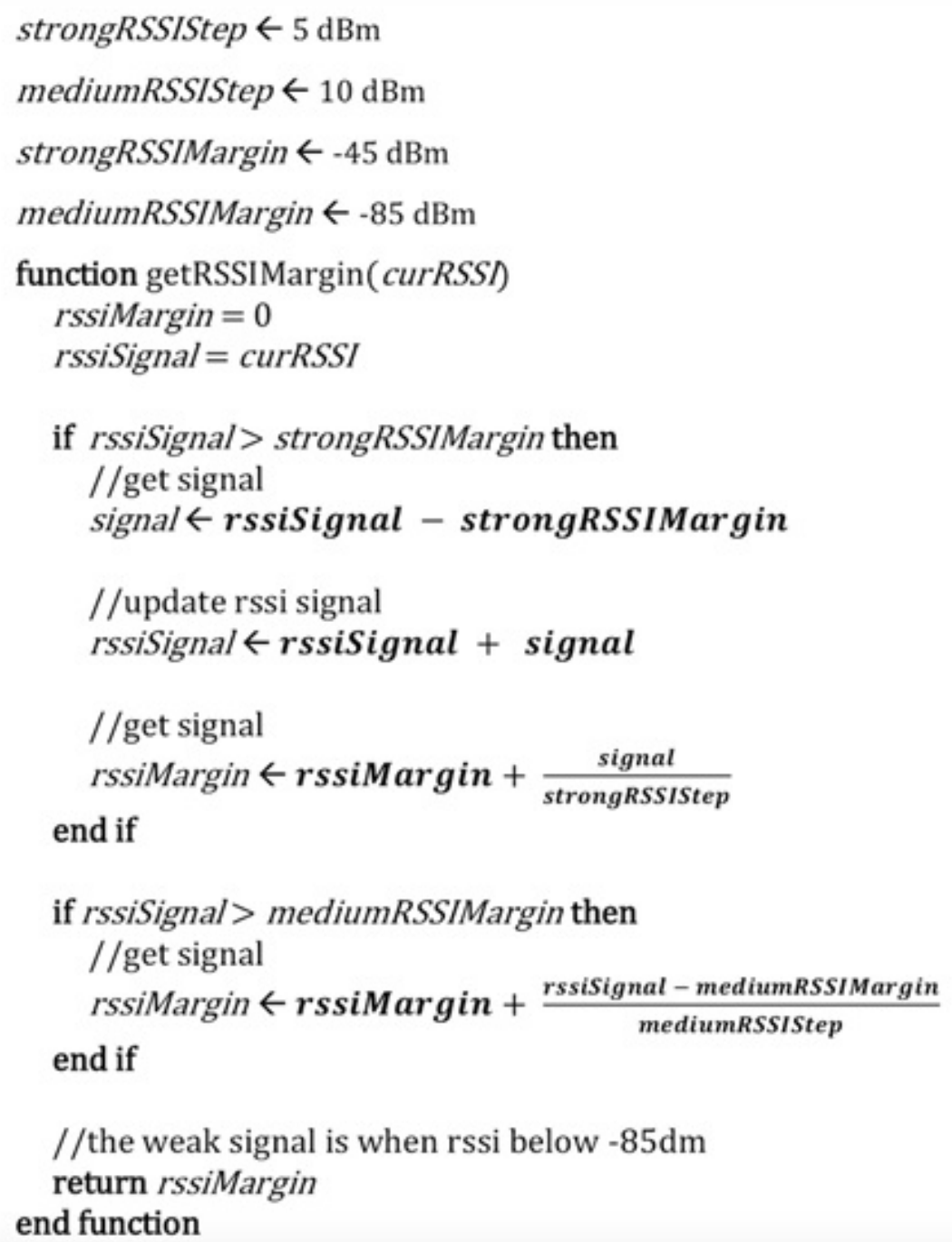

Figure 3: Optimal function for ADR algorithm.

- A gateway device.

- A LoRaTM network server.

- A data analysis application.

In this system, We developed the air quality sensor and the gateway by using open and easily accessible hardware accompanying with open-source software. The network server and the application server also built with renown open-source frameworks to easy on development and deployment.

The air quality sensor shown in Figure 6, which included hardware components as following:

- MSP430FR5994, an ultra-low-power MCU from Texas Instruments.
- Grove - Laser PM2.5, an air quality sensor from Seed.

- S76SXB, a LoRaWANTM certified module.

- A 3.7V 2000mAh Lithium-Ion battery.

The gateway structure outlined in Figure 7, which constructed by a combination of a Raspberry Pi 3 Model B+ with a RAK831 LoRa ${ }^{T M}$ gateway module. The network server and application server deployed on cloud computing service of Digital Ocean. The network server was running framework The Things Network with LoRaWANTM version 1.1.

\section{Device configuration.}

In the experiment section, the study wanted to focus on assessing energy optimization capabilities, as well 


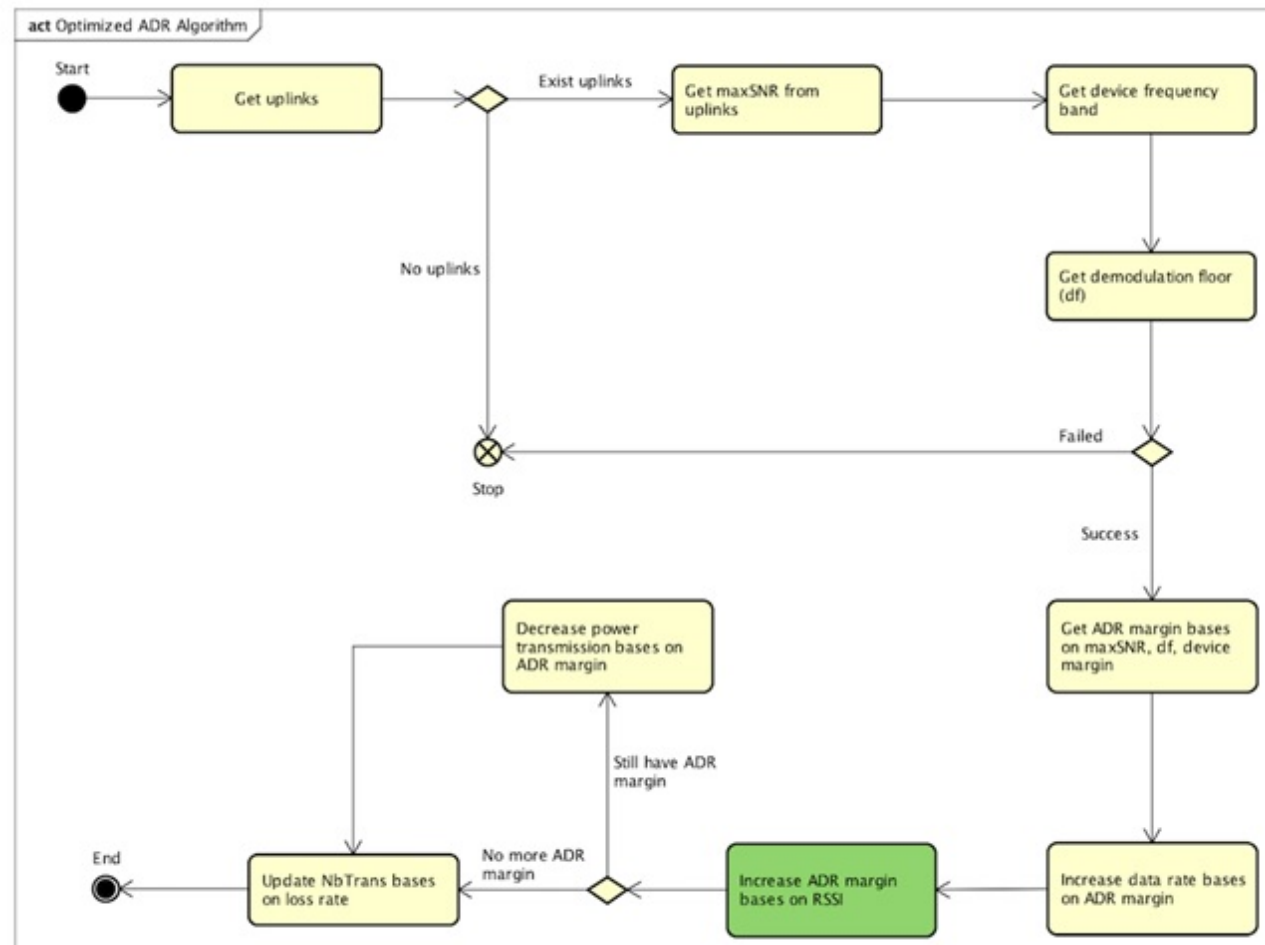

Figure 4: Optimal function for ADR algorithm.

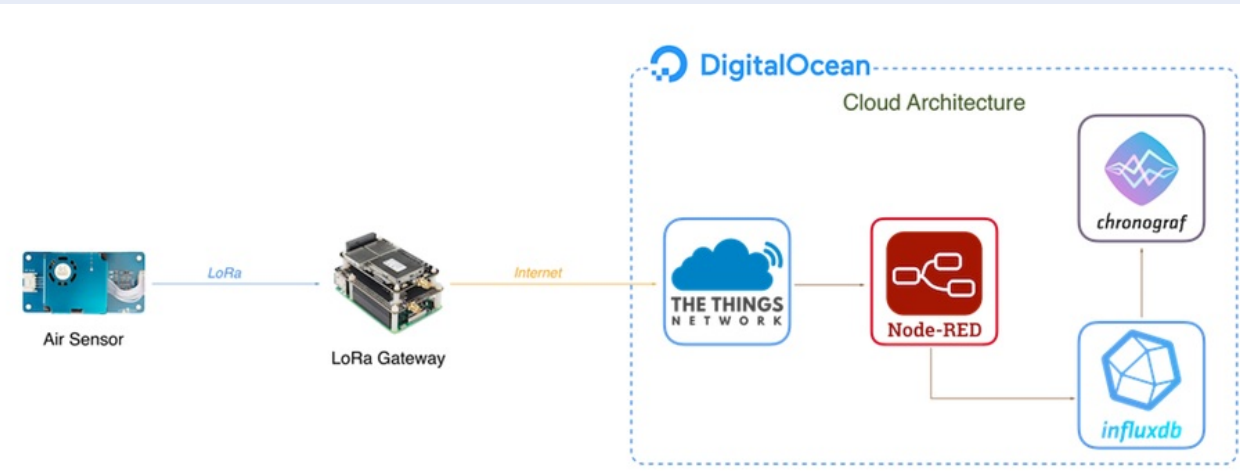

Figure 5: The LoRa ${ }^{T M}$ infrastructure overview.

as finding out the limitations of the proposed solution. The LoRa ${ }^{T M}$ gateway and the air quality sensor in the experiments configured as follows:

The gateway located 20 meters above the ground and connected to the internet via Wi-Fi. This device configured to operate on eight channels of EU868MHz frequency band in Table 3.

The air quality sensor was set up with the following information:
- Automatically join the network via over-the-airactivation (OTAA) mechanism.

- Operation on $867.5 \mathrm{MHz}$ frequency band.

- Initial spreading factor (SF) at 12.

- Initial transmission power at $16 \mathrm{dBm}$.

- Enabled adaptive data rate feature.

- Sending air data with the un-confirm configuration. 


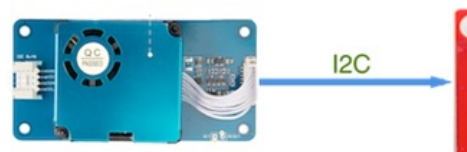

Laser PM2.5 Sensor

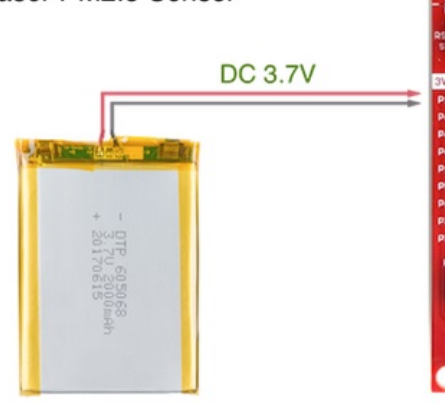

Battery

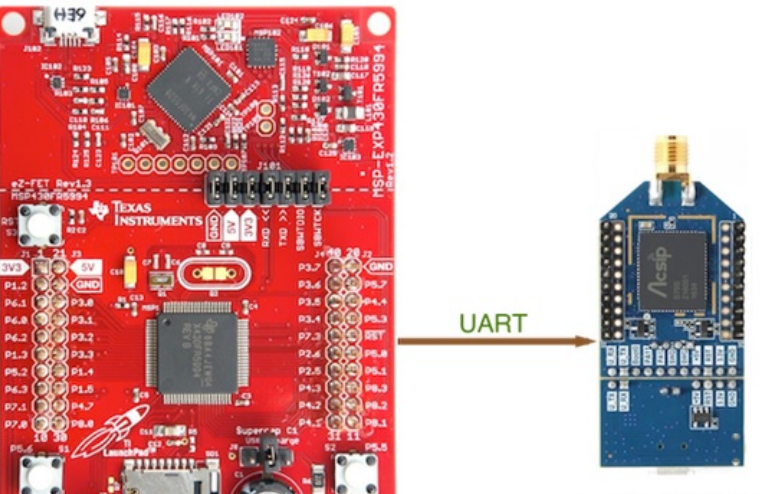

LoRa S76SXB

Figure 6: The air quality sensor structure.

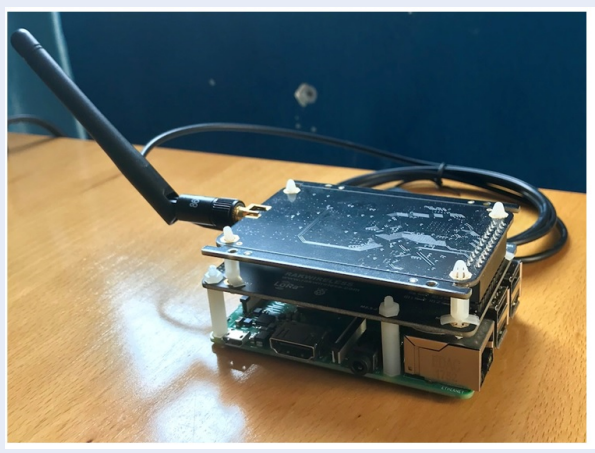

Figure 7: The LoRa ${ }^{T M}$ gateway.

Table 3: The configuration channel of the gateway

\begin{tabular}{lll}
\hline $\begin{array}{l}\text { Channel Num- } \\
\text { ber }\end{array}$ & Bandwidth & Frequency \\
1 & $125 \mathrm{kHz}$ & $868.1 \mathrm{MHz}$ \\
2 & $125 \mathrm{kHz}$ & $868.3 \mathrm{MHz}$ \\
3 & $125 \mathrm{kHz}$ & $868.5 \mathrm{MHz}$ \\
4 & $125 \mathrm{kHz}$ & $867.1 \mathrm{MHz}$ \\
5 & $125 \mathrm{kHz}$ & $867.3 \mathrm{MHz}$ \\
6 & $125 \mathrm{kHz}$ & $867.5 \mathrm{MHz}$ \\
7 & $125 \mathrm{kHz}$ & $867.7 \mathrm{MHz}$ \\
8 & $125 \mathrm{kHz}$ & $867.9 \mathrm{MHz}$ \\
\hline
\end{tabular}

- Powered by a 3.7V - 2000 mAh Lithium-Ion battery.

\section{Experiments}

\section{Experiment 1}

The goal of this work measured and compared the power consumption of the proposed solution and original algorithm of The Things Network in shortrange. The result presented in Figure 8.

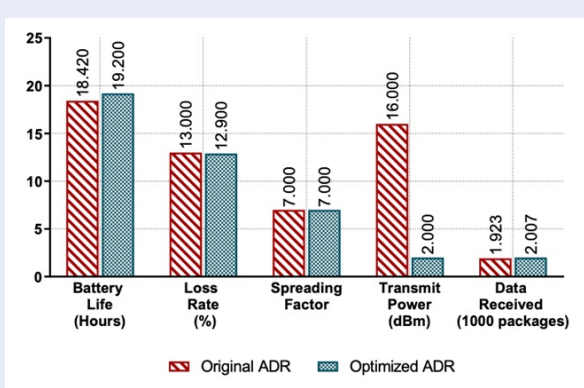

Figure 8: The result of experiment 1.

Based on the results of the experiment, the following assessments concluded:

- The battery life of the sensor with the proposed solution was 4 percent longer than the original algorithm. 
- The amount of data received at the gateway was also more than 4 percent corresponding to the lifetime.

- The loss rate was utterly equivalent to the original algorithm.

- The transmission power difference could reach up to $14 \mathrm{dBm}$, according to the evaluation, it saved $7.6 \mathrm{~mA}$ per transmission.

\section{Experiment 2}

The second experiment aimed to evaluate the proposed solution within medium range in the city environment. The result illustrated in Figure 9.

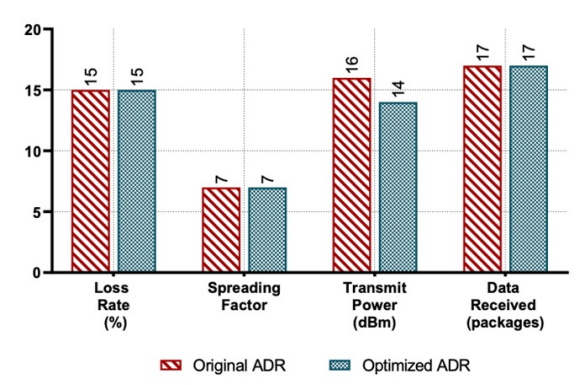

Figure 9: The result of experiment 2.

Based on the experimental result, we stated some information:

- In the medium range, the solution still able to save energy but with a few amounts of energy.

- The transmission power saved by the solution was $2 \mathrm{dBm}$.

\section{Experiment 3}

The third experiment explained to the efficiency of the solution within a long-range. The result described in Figure 10.

With the result from experiment 3, we had a conclusion that the proposed solution did not affect the communication range of the end devices. The distance map displayed in Figure 11.

\section{DISCUSSION}

The paper studied and proposed a solution to optimize energy consumption in the wireless sensor network using LoRa ${ }^{T M}$ technology and LoRaWAN ${ }^{T M}$ network protocol. The study also introduced a typical LoRa ${ }^{T M}$ infrastructure with components: air quality sensor, gateway, network servers, and application server. From the result of experiments, there were some advantages as below:

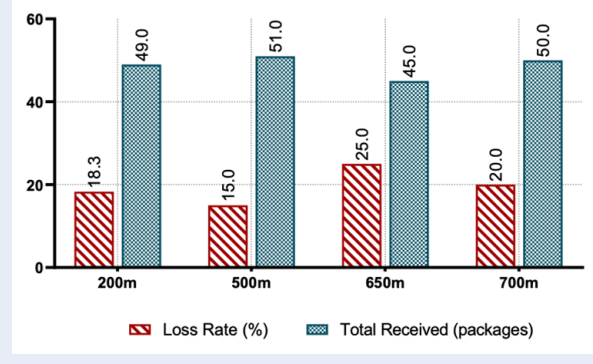

Figure 10: The result of experiment 3.

- Implemented in the network server, so there was no limit on the end devices.

- The solution only optimizes energy consumption, did not affect the transmission quality and the loss rate.

- In the experiment, the saving-power could be up to $14 \mathrm{dBm}$ per transmission, and this could extend the battery life of the end device to 4 percent.

- High applicability, because of requiring no hardware changes and some minor updates in software.

- There was some limitation of the proposed solution. We summarized as below:

- Apply more excellent techniques (machine learning, big data) to be able to find the most optimal transmission power level with the least uplink package, to limit the number of downlinks to save more energy.

- The optimal function reduced power transmission step by step, so it required more downlink to control the transmission parameters on the end devices.

- This solution required the end devices enabled the adaptive data rate feature.

- The solution built on the foundation of LoRaWAN $^{T M}$ network protocol so that it applied to $\mathrm{LoRa}^{T M}$ systems only.

\section{CONCLUSIONS}

In this paper, we proposed an adaptive algorithm to save energy consumption of a LoRa-based system while keeping communication quality unchanged. The best point of the solution was studying and developing based on the LoRaWAN ${ }^{T M}$ network protocol 


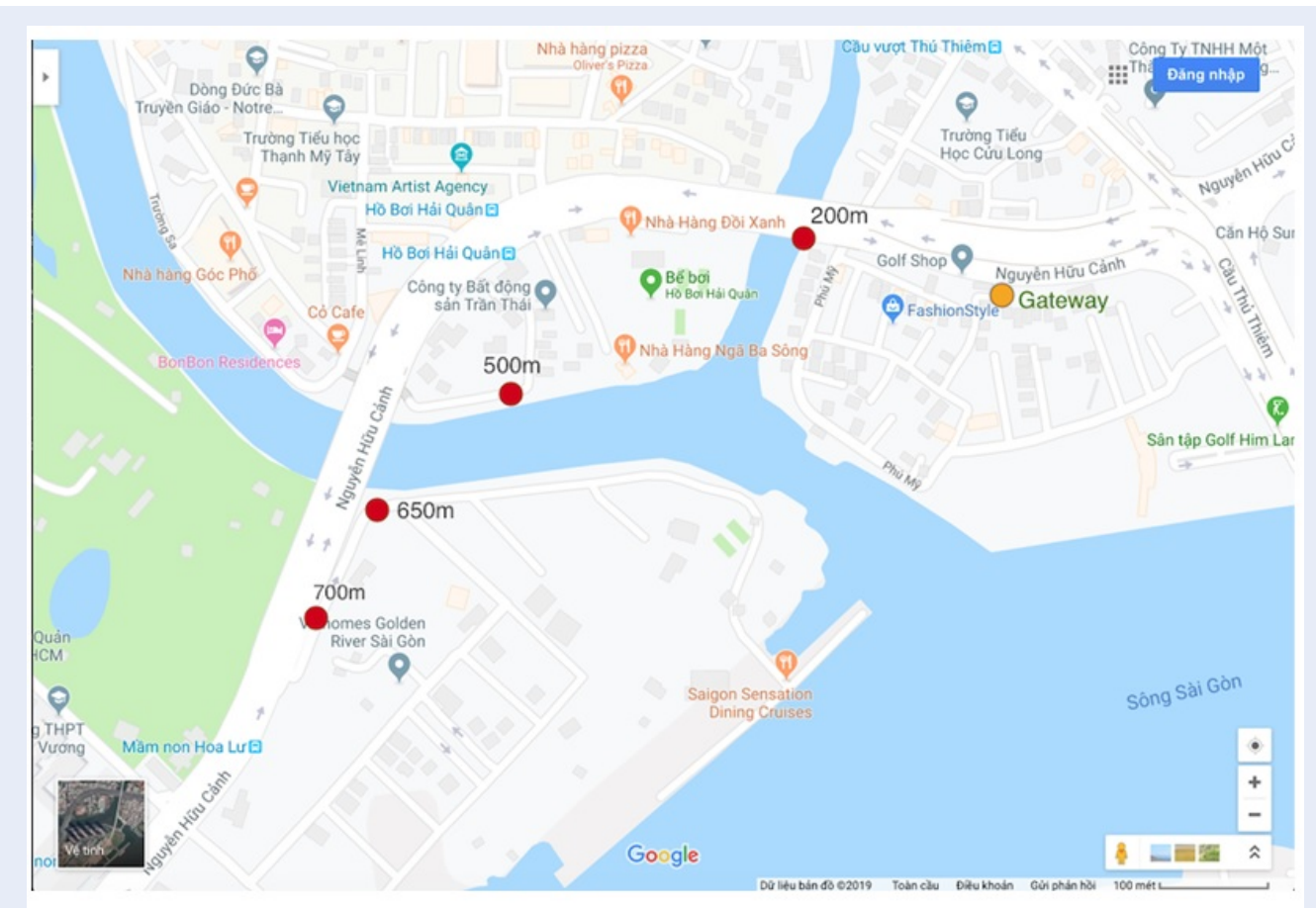

Figure 11: The distance map in experiment 3.

so it could be expanded and improved without limitation on any hardware. Based on the limitations, some further research directions may be conducted to optimize the current solution, for example using additional sensitivity information of the gateway to optimize, since gateways with different hardware could be received data at different transmission power.

\section{ACKNOWLEDGENMENT}

This research is funded by Department of Science and Technology of Ho Chi Minh City under grant number 09/2018/HD-QKHCN.

\section{ABBREVIATION}

ADR: Adaptive Data Rate

IP: Internet protocol

ISM: Industrial, Scientific \& medical

OTAA: Over the air activation

RSSI: Radio signal strength indication

TNN: The Things Network

WSN: Wireless sensor network

WuR: Wake-up Radio

\section{CONFLICT OF INTEREST}

The authors declare that there is no conflict of interest.

\section{AUTHORS' CONTRIBUTIONS}

Le Cong Nga proposed the algorithm and implement the experiments. Cuong Pham-Quoc proposed the idea and structure of the paper. Tran Ngoc Thinh checked the algorithm and verify the experiments. All authors wrote and proof-read.

\section{REFERENCES}

1. Wixted AJ, Kinnaird P, Larijani $H$, Tait A, Ahmadinia A, Strachan N. Evaluation of LoRa and LoRaWAN for wireless sensor networks. SENSORS, IEEE. 2016;p. 1-3. Available from: https: //doi.org/10.1109/ICSENS.2016.7808712.

2. Rizzi M, Ferrari P, Flammini A, Sisinni E, Gidlund M. Using LoRa for industrial wireless networks. Proc IEEE 13th Int Workshop Factory Commun Syst (WFCS). 2017;p. 1-4. PMID: 28039784 Available from: https://doi.org/10.1109/WFCS.2017.7991972.

3. Aoudia FA, Magno M, Gautier M, Berder O, Benini L. A Low Latency and Energy Efficient Communication Architecture for Heteroge-neous Long-Short Range Communication. 2016 Euromicro Conference on Digital System Design. 2016;p. 200206. Available from: https://doi.org/10.1109/DSD.2016.97.

4. Hauser V, Hegr T. Proposal of Adaptive Data Rate Algorithm for LoRaWAN-based Infrastructure. IEEE 5th International Conference on Future Internet of Things and Cloud. 2017;Available from: https://doi.org/10.1109/FiCloud.2017.47.

5. Slabicki M, Premsankar G, Francesco MD. Adaptive Configuration of LoRa Networks for Dense IoT Deployments, NOMS 2018. IEEE/IFIP Network Operations and Management Symposium. 2018;Available from: https://doi.org/10.1109/NOMS. 2018.8406255.

6. Bor M, Roedig U. LoRa Transmission Parameter Selection. 13th International Conference on Distributed Computing in Sensor Systems. 2017;Available from: https://doi.org/10.1109/DCOSS. 2017.10.

7. Adaptive Data Rate;Available from: http://thethingsnetwork. org/wiki/LoRaWAN/ADR. 
8. How does RSSI (dBm) relate to signal quality (percent);Available from: https://www.speedguide.net/faq/how-does-rssi-dbmrelate-to-signal-quality-percent- 439.
9. LoRaWANTM Specification version 1.1. 2017;Available from: https://lora-alliance.org/resource-hub/lorawantm- 


\title{
Giải pháp tiết kiệm năng lượng cho công nghệ giao tiếp không dây tầm xa
}

\author{
Lê Công Ngà, Phạm Quốc Cường ${ }^{*}$, Trần Ngọc Thịnh
}

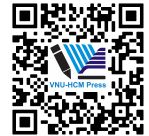

Use your smartphone to scan this

QR code and download this article

Trường Đại Học Bách khoa - Đại học Quốc Gia Thành Phố Hồ Chí Minh

Liên hệ

Phạm Quốc Cường, Trường Đại Học Bách khoa - Đại học Quốc Gia Thành Phố Hô Chí Minh

Email: cuongpham@hcmut.edu.vn

Lịch sử

- Ngày nhận: 05-8-2019

- Ngày chấp nhận: 03-9-2019

- Ngày đăng: 13-11-2020

DOI :10.32508/stdjet.v3i3.532

\section{Check for updates}

\section{Bản quyền}

๑ ĐHQG Tp.HCM. Đây là bài báo công bố mở được phát hành theo các điều khoản của the Creative Commons Attribution 4.0 International license.

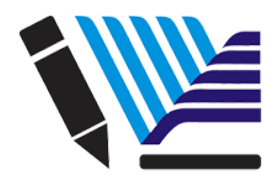

VNU-HCM Press

\section{TÓM TẮT}

Theo các nghiên cứu gần đây, mạng cảm biến không dây (Wireless Sensor Network) tiêu thụ năng lượng thấp sẽ ngày càng trở nên phổ biến, thúc đẩy xu hướng nghiên cứu về tối ưu hoá năng lượng cho mạng cảm biến không dây tăng nhanh. Công nghệ LoRa ${ }^{T M}$ là một công nghệ điều chế sóng mang đến khả năng truyền tải dữ liệu ở khoảng cách xa với mức yêu cầu năng lượng thấp, thêm vào đó LoRaWAN ${ }^{T M}$ là một giao thức mạng dựa trên công nghệ LoRa ${ }^{T M}$ được thiết kế nhằm ưu hoá cho các thiết bị hoạt động dựa trên nguồn năng lượng là pin. Hai công nghệ này được đánh giá là giải pháp phù hợp cho mạng cảm biến không dây, giúp giảm mức năng lượng tiêu thụ và mở rộng tâmm hoạt động. Trong thời đại hậu máy tính cá nhân, khi các thiết bị chủ yếu sử dụng pin thì việc tiết kiệm năng lượng là một trong những yếu tố rất quan trọng và hấp dẫn người sử dụng. Trong bài báo này, chúng tôi nghiên cứu về kỹ thuật thích ứng trong thiết lập các thông số truyền tải dữ liệu của mạng LoRa ${ }^{T M}$ và đề xuất một giải pháp tiết kiệm năng lượng cho giải thuật thích ứng. Giải thuật của chúng tôi giúp tiết kiệm năng lượng nhưng vẫn giữ nguyên chất lượng truyền dẫn theo giao thức LoRa. Nghiên cứu này giới thiệu một phần cứng mẫu của một nút cảm biến trong mạng cảm biến không dây, cũng như hiện thực một hệ thống mạng LoRa ${ }^{T M}$ điển hình. Chúng tôi tiến hành ba thí nghiệm khác nhau với các cảm biến chất lượng không khí và các bo mạch MCU của hãng Texas instrument. Các thí nghiệm của chúng tôi được tiến hành với hệ thống thực và mô phỏng đêu cho kết quả tốt với tối thiểu $4 \%$ năng lượng được tiết kiệm. Mặc dù tiết kiệm năng lượng nhưng chất lượng truyền dẫn về khoản cách và tî lệ gói tin đến đều được giũ nguyên. Các hệ thống thực nghiệm và giải thuật có thể được dùng cho các nghiên cứu khác cùng chủ đề. Ngày nay, càng tiết kiệm năng lượng sẽ̃ càng làm cho thế giới xanh hơn.

Từ khoá: LoRaTM, LoRaWANTM, Mạng Cảm Biến Không Dây, Tốc Độ Dữ Liệu Thích Ứng, Tiết Kiệm Năng Lượng
Trích dẫn bài báo này: Ngà $\mathrm{L} C$, Cường $\mathrm{P} Q$ Thịnh $\mathrm{T} N$ Gải pháp t iết kiệm năng I ượng cho công nghệ giao tiếp không dây $\mathbf{t}$ ầm xa. Sci. Tech. Dev. J. - Eng. Tech.; 3(SI1):SI59-SI70. 